\title{
Long-term results of right ventricular outflow tract reconstruction in neonatal cardiac surgery: Options and outcomes
}

\author{
Aditya K. Kaza, MD, Hong-Gook Lim, MD, Daniel J. Dibardino, MD, Victor Bautista-Hernandez, MD, \\ Joshua Robinson, MD, Catherine Allan, MD, Peter Laussen, MBBS, Francis Fynn-Thompson, MD, \\ Emile Bacha, MD, Pedro J. del Nido, MD, John E. Mayer, Jr, MD, and Frank A. Pigula, MD
}

Objectives: Neonatal surgery for tetralogy of Fallot and truncus arteriosus requires reconstruction of the right ventricular outflow tract. Although the method of reconstruction is often dictated by the individual anatomy, choices exist. This review examines the durability and outcomes of right ventricular outflow tract reconstruction in the neonate.

\begin{abstract}
Methods: This is a retrospective review of all 278 neonates with the diagnosis of tetralogy of Fallot and truncus arteriosus undergoing right ventricular outflow tract reconstruction at a single center between 1990 and 2007. Diagnostic variants included tetralogy of Fallot/pulmonary stenosis $(n=83)$, tetralogy of Fallot/pulmonary atresia $(\mathrm{n}=81)$, and tetralogy of Fallot with absent pulmonary valve $(\mathrm{n}=17)$. Truncus arteriosus was present in 97 patients. Patients were analyzed on the basis of diagnosis and the method of right ventricular outflow tract reconstruction: aortic homograft, pulmonary homograft, transannular patch, transannular patch with monocusp pulmonary valve, and nontransannular patch. Freedom from reoperation/reintervention was determined by using the log-rank test.
\end{abstract}

Results: The mean age at right ventricular outflow tract reconstruction was $11.8 \pm 8$ days, and hospital survival was $95.0 \%$ for the tetralogy of Fallot group and $90.7 \%$ for the truncus arteriosus group. Overall freedom from reoperation and reintervention was $76.2 \% \pm 14.8 \%$ in the nontransannular patch group and $59.5 \% \pm 6.8 \%$ in the transannular patch group; both were significantly greater than seen in patients receiving either aortic $(0 \%)$ or pulmonary $(6.7 \% \pm 4.2 \%)$ homografts $(P<.05)$. There was no difference between aortic and pulmonary homografts. Among patients with tetralogy of Fallot/pulmonary stenosis, there was no difference in 10-year freedom from reoperation/reintervention between the transannular $(70.8 \% \pm 7.4 \%)$ and nontransannular patch methods $(76.2 \% \pm 14.8 \%, P=.53)$. At 10 years, the diagnosis of tetralogy of Fallot/pulmonary stenosis was associated with a greater freedom from reoperation/reintervention $(68 \% \pm 6.8 \%)$ when compared with tetralogy of Fallot/pulmonary atresia $(5.3 \% \pm 4.3 \%, P=.0001)$, tetralogy of Fallot/absent pulmonary valve $(0 \%$, $P=.00315)$, or truncus arteriosus $(4.2 \% \pm 2.8 \%, P=.0001)$. Eight patients (4 with tetralogy of Fallot $/$ pulmonary stenosis, 3 with tetralogy of Fallot/pulmonary atresia, and 1 with tetralogy of Fallot/absent valve) underwent placement of a transannular patch with monocusp valve. Among this group, freedom from reoperation/reintervention is $41.7 \% \pm 20.5 \%$ at 2.5 years. Monocusp function, as determined by means of echocardiographic analysis obtained at $11.4 \pm 11.7$ months (range, $0.3-31$ months) showed an average monocusp gradient of $23.5 \pm 26.1$ $\mathrm{mm} \mathrm{Hg}$, and $3(37.5 \%)$ patients had more than moderate pulmonary regurgitation.

Conclusions: The durability of neonatal right ventricular outflow tract reconstruction is diagnosis and method dependent. Anatomy allowing right ventricular outflow tract patching (either transannular or nontransannular) provides a durability advantage compared with that seen with a homograft. There was no difference in performance between aortic and pulmonary homografts, and the monocusp valve has limited durability and effectiveness in neonatal right ventricular outflow tract surgery. The long-term outcomes of transannular and nontransannular patching techniques for neonatal repair of tetralogy of Fallot/pulmonary stenosis are similar.

\footnotetext{
From the Division of Cardiac Surgery and Cardiology, Children's Hospital Boston and Harvard Medical School, Boston, Mass.

Read at the Annual Meeting of the Western Thoracic Surgical Association, Kona, Hawaii, June 25-28, 2008.

Received for publication June 23, 2008; revisions received Sept 16, 2008; accepted for publication Oct 13, 2008; available ahead of print July 27, 2009.

Address for reprints: Frank A. Pigula, MD, Division of Cardiac Surgery, Children's Hospital Boston, 300 Longwood Ave, Bader 273, Boston, MA 02115 (E-mail: frank.pigula@cardio.chboston.org).

J Thorac Cardiovasc Surg 2009;138:911-6

$0022-5223 / \$ 36.00$

Copyright (c) 2009 by The American Association for Thoracic Surgery

doi:10.1016/j.jtcvs.2008.10.058
}

Reconstruction of the right ventricular outflow tract (RVOT) is a common constituent of neonatal cardiac surgery. With the trend toward early repair and palliation of the RVOT ${ }^{1,2}$ in lesions including tetralogy of Fallot (TOF) and truncus arteriosus (TA), reconstruction of the RVOT has become more commonplace. A variety of techniques to achieve right ventricle-pulmonary artery continuity has been devised, and the method used is often determined by patient-specific anatomy. The methods of RVOT reconstruction include patching (transannular \pm monocusp valve and nontransannular) 


$$
\begin{aligned}
& \text { Abbreviations and Acronyms } \\
& \begin{aligned}
\text { APV } & =\text { absent pulmonary valve } \\
\text { PA } & =\text { pulmonary atresia } \\
\text { PS } & =\text { pulmonary stenosis } \\
\text { RVOT } & =\text { right ventricular outflow tract } \\
\text { TA } & =\text { truncus arteriosus } \\
\text { TOF } & =\text { tetralogy of Fallot } \\
\text { VSD } & =\text { ventricular septal defect }
\end{aligned}
\end{aligned}
$$

and the use of a biologic right ventricle-pulmonary artery conduit (aortic homograft, pulmonary homograft, or bovine jugular vein graft). ${ }^{3-7}$

We sought to determine the durability of the various methods of RVOT reconstruction performed in the neonatal period. Specifically, freedom from reoperation and reintervention as a consequence of diagnosis and method of repair was determined, and we sought to identify clinical variables that might influence the durability of neonatal RVOT reconstructions.

\section{MATERIALS AND METHODS}

Institutional review board approval was obtained for the conduct of this study. The study is a retrospective review of the cardiology/cardiac surgery database, identifying all neonates who underwent RVOT reconstruction at Children's Hospital Boston from 1990 to 2007. Medical charts, operative records, postoperative reintervention reports, echocardiographic and angiographic data, and correspondence with the pediatrician were reviewed. The patient data were then analyzed on the basis of diagnosis and the method used for RVOT reconstruction. Reintervention was defined as catheter based or surgical, with the intervention target being the RVOT. Freedom from death or reintervention as a function of diagnosis and the method of RVOT reconstruction was estimated by using multivariate analysis. Differences were determined by using either the log-rank test or $\chi^{2}$ analysis.

Between 1990 and 2007, 278 patients less than 30 days of age and undergoing surgical reconstruction of the RVOT were identified. There were 181 patients with TOF and 97 patients with TA. Diagnostic variants included TOF with pulmonary stenosis (PS; $\mathrm{n}=83$ ), TOF with pulmonary atresia (PA; $\mathrm{n}=81$ ), and TOF with absent pulmonary valve (APV; $\mathrm{n}=$ 17). TA was present in 97 patients, and patients were classified according to the Van Praagh classification. ${ }^{8}$ Freedom from death and reintervention was analyzed, and intragroup comparisons were made.

\section{RESULTS}

The mean age at the time of the operation for this group was $11.8 \pm 8.2$ days (range, $1-31$ days; median, 9 days). The in-hospital survival for the entire group was $93.5 \%$ (260/278). There was a trend toward greater survival in the later era, but this did not reach statistical significance (90.6\% for $1990-1997$ vs $96.0 \%$ for $1997-2007, P=$ .06949).

The TOF group of 181 patients consisted of the various subsets indicated in Table 1. The average age at repair was $12.3 \pm 8.8$ days (range, $1-31$ days; median, 10 days). The in-hospital survival for the TOF group was $95.0 \%(172 /$
181). Once again, there was no era effect when comparing survival during 1990 to 1997 and that during 1998 to 2007 (93.5\% vs $96.1 \% ; P=.41789, \chi^{2}$ test $)$.

The method of RVOT reconstruction among patients with TOF included transannular patching in 97 (53.6\%) patients, a pulmonary homograft in $38(20.9 \%)$ patients, an aortic homograft in $34(18.7 \%)$ patients, a nontransannular patch in $11(6 \%)$ patients, and a valved bovine jugular vein graft in $1(0.6 \%)$ patient. The term nontransannular patch is used to describe repairs that do not disrupt the pulmonary valve annulus. Although this terminology generally refers to a pulmonary arteriotomy in isolation, in some instances both a pulmonary arteriotomy and an infundibulotomy were performed without breaching the pulmonary annulus.

In the TOF/PS group (83 patients) 69 (83.1\%) patients underwent transannular patch placement, 11 (13.1\%) patients underwent nontransannular patch placement, and $3(3.6 \%)$ patients had an aortic homograft inserted. In the TOF/APV group (17 patients) $8(47.1 \%)$ patients had a pulmonary homograft reconstruction, $5(29.4 \%)$ patients had transannular patch placement, and $4(23.5 \%)$ patients had an aortic homograft used for reconstruction. In the TOF/ PA group (81 patients) $30(37 \%)$ patients had a pulmonary homograft, 27 (33.3\%) patients had an aortic homograft, 23 $(28.4 \%)$ patients had a transannular patch, and $1(1.2 \%)$ patient had a valved bovine jugular vein graft. One hundred sixty-five patients had a ventricular septal defect (VSD) closed in the TOF group in addition to the RVOT procedure; it was closed with a fenestrated patch in 4 patients. The VSD was left open in 16 patients ( 9 patients with TOF/PA/diminutive pulmonary arteries, 5 patients with TOF/PA, 1 patient with TOF/PA/discontinuous pulmonary arteries, and 1 patient with TOF/PS). Seventy-nine patients underwent reintervention or reoperation. Of these, 66 patients had catheter-based reinterventions, and 59 patients had reoperations (Figure 1). Among the 59 patients who had a reoperation, 33 had conduit change, 16 had augmentation of the RVOT, 3 had repair of an RVOT pseudoaneurysm, 2 had pulmonary valve implantation (secondary to increased right ventricular volumes, as noted on magnetic resonance imaging), 2 had conduit revision, 2 had left pulmonary artery augmentation, and 1 had augmentation of the main pulmonary artery.

Of the 59 patients who had reoperations, $47 \mathrm{had}$ a diagnosis of TOF/PA, and 6 patients each had a diagnosis of TOF/PS and TOF/APV (Figure 2). Of the 47 patients with TOF/PA who had reoperations, 25 had conduits changed, and the rest had augmentation of the main pulmonary artery, RVOT, and/or branch pulmonary arteries. Of the 6 patients with TOF/PS who had reoperations, 2 had a conduit change, and the rest had augmentation of the RVOT. Of the 6 patients with TOF/APV who had reoperations, 5 underwent conduit replacement, and 1 had an RVOT false aneurysm repaired. 
TABLE 1. Specific diagnoses of patients in the TOF group

\begin{tabular}{lc}
\hline \multicolumn{1}{c}{ TOF group } & $\mathbf{n}=\mathbf{1 8 1}$ \\
\hline TOF/PS & 83 \\
TOF/PS & 75 \\
TOF/PS/discontinuous pulmonary artery & 6 \\
TOF/PS/aortopulmonary window & 2 \\
TOF/APV & 17 \\
TOF/APV & 15 \\
TOF/APV/discontinuous pulmonary artery & 2 \\
TOF/PA & 81 \\
TOF/PA & 67 \\
TOF/PA/diminutive pulmonary artery & 9 \\
TOF/PA/discontinuous pulmonary artery & 3 \\
TOF/PA/aortopulmonary window & 1 \\
TOF/PA/discontinuous and diminutive pulmonary arteries & 1 \\
\hline TOF, Ttrlogy of
\end{tabular}

$T O F$, Tetralogy of Fallot; $P S$, pulmonary stenosis; $A P V$, absent pulmonary valve; $P A$, pulmonary atresia.

The percentage of patients requiring reoperations in the TOF group was $32.5 \%(59 / 181)$; it was $47 \%(47 / 81)$ in the TOF/PA group, $7.2 \%(6 / 83)$ in the TOF/PS group, and $35.2 \%(6 / 17)$ in the TOF/APV group. The catheter-based reintervention rate was $36.4 \%(66 / 181)$ for the entire TOF group, $58 \%(47 / 81)$ in the TOF/PA group, $16.8 \%(14 / 83)$ in the TOF/PS group, and $29.4 \%(5 / 17)$ in the TOF/APV group.

The freedom from reoperation was $88.9 \% \pm 10.5 \%$ at 16 years in the nontransannular patch group and $63 \% \pm 14.9 \%$ at 14 years on the transannular patch group $(P=.3720$, log-rank test). The freedom from both reoperation and reintervention was $76.2 \% \pm 14.8 \%$ at 16 years in the nontransannular patch group and $59.5 \% \pm 6.8 \%$ at 14 years in the transannular patch group $(P=.2325, \log$-rank test). Freedom from both catheter-based reintervention and reoperation was $68.0 \% \pm 6.8 \%$ at 16 years in the TOF/PS group, $5.3 \% \pm 4.3 \%$ at 14 years in the TOF/PA group, $0.0 \%$ at 3.4 years in the TOF/APV group, and $4.2 \% \pm 2.8 \%$ at 14 years in the TA group. The TOF/PS group had a longer freedom from reintervention and reoperation when compared with the TOF/PA $(P=.0001)$ TOF/APV $(P=.0315)$, and TA $(P=.0001$, log-rank test $)$ groups.

We examined the subgroup of patients who had transannular patching with or without monocusp valve construction. Eight patients underwent transannular patch placement with a monocusp, 4 of whom had TOF/PS, 3 of whom had TOF/PA, and 1 who had TOF/APV. At followup echocardiographic analysis at $11.4 \pm 11.7$ months (range, $0.3-31$ months) after the operation, the mean gradient was $23.5 \pm 26.1 \mathrm{~mm} \mathrm{Hg}$ (range, $0-65 \mathrm{~mm} \mathrm{Hg}$ ), with 2 patients having a gradient of more than $30 \mathrm{~mm} \mathrm{Hg}$, and 3 patients having more than moderate pulmonary regurgitation. There was no difference in reintervention and reoperation rates in the transannular patch with monocusp reconstruction group versus The transannular patch without monocusp reconstruction group $(41.7 \% \pm 20.5 \%$ at 2.6 years vs $68.2 \% \pm$

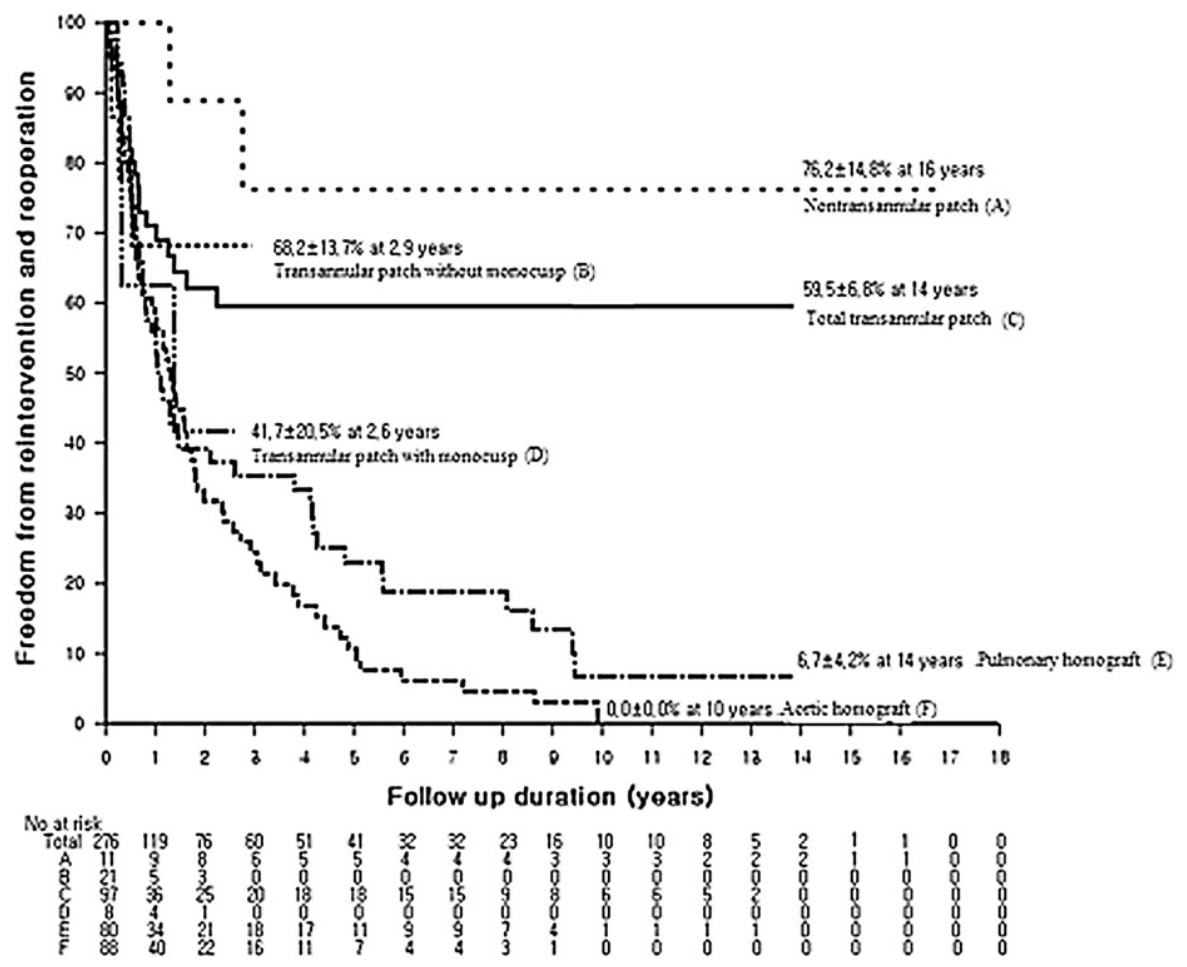

FIGURE 1. Freedom from reintervention and reoperation based on the type of right ventricular outflow tract reconstruction. 

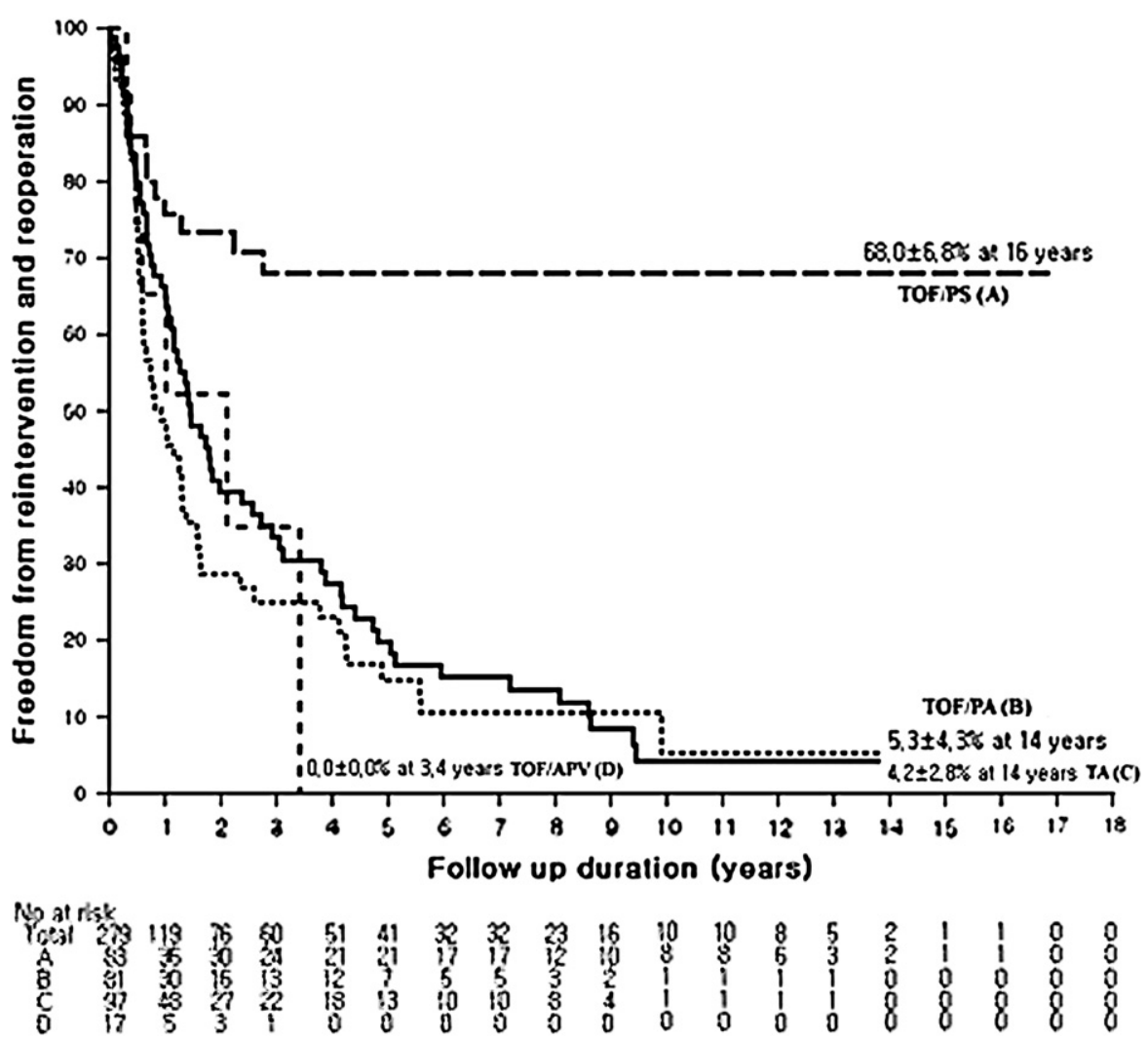

FIGURE 2. Freedom from reintervention and reoperation based on the primary diagnosis requiring right ventricular outflow tract reconstruction. TOF, Tetralogy of Fallot; $P S$, pulmonary stenosis; $A P V$, absent pulmonary valve; $P A$, pulmonary atresia; $T A$, truncus arteriosus.

$13.7 \%$ at 2.9 years; $P=.5886, \log$-rank test). Patients who had RVOT reconstruction with either an aortic or pulmonary homograft had significantly shorter freedom from reintervention or reoperation when compared with those undergoing all other types of RVOT reconstruction.

Ninety-seven patients with TA were included in this analysis. This included 46 patients with type IA, 31 patients with type IIA, 4 patients with type IIIA, and 16 patients with type IVA TA. The age at repair was $10.8 \pm 7.1$ days (range, $2-31$ days; median, 9 days). Given the variable and increased pulmonary vascular resistance in the newborn period, we prefer using homograft conduits in TA repair. The type of RVOT procedure was an aortic homograft in $54(55.7 \%)$ patients and a pulmonary homograft in $42(43.3 \%)$ patients, and 1 patient had a valved bovine jugular vein graft $(1 \%)$. The VSD was closed in all patients. The in-hospital survival was $90.72 \%$ (88/97 patients). Again, although there was a trend toward improved survival according to era (19901997 vs $1998-2007: 86.28 \%$ vs $95.65 \% ; P=.11193, \chi^{2}$ test), this did not reach statistical significance. Fifty-six patients in the TA group underwent reoperations during the course of the study, and 54 patients underwent catheterbased reinterventions. The vast majority of reoperations were for conduit change, and the majority of catheter reinterventions were for conduit dilation.

\section{DISCUSSION}

RVOT reconstruction is required in the management of neonates with a variety of congenital heart diseases. We examined the type of RVOT reconstruction and the durability of these reconstructions when performed in the neonatal period for TOF and TA. The durability results for TA have remained stable over the years, and our series reflected the overall improved survival in the management of this lesion when compared with historical series. ${ }^{9}$ The majority of patients with TOF/PS had transannular patch reconstruction of the RVOT, and when compared with the other types of patients with TOF, the TOF/PS group with transannular patch reconstruction had the most durable RVOT reconstruction. The majority of patients in the TOF/PA and TOF/APV groups had the RVOT reconstructed with a valve conduit; they had a significantly lower freedom from reintervention and reoperation when compared with the TOF/PS group.

The indications for reoperation are varied in this diverse group. For patients undergoing reparative surgical intervention, our general practice is to proceed with reintervention when the RVOT gradient exceeds three quarters of systemic pressure. Reintervention for palliated patients (ie, TOF/PA with open VSD) was more complicated, including the Qp:Qs and the ability to unifocalize aortopulmonary 
collateral arteries. All decisions with regard to reintervention are unique in that they incorporate multiple factors, such as ventricular function, tricuspid valve function, and right ventricular dimensions. Examining the durability of the RVOT reconstruction based on the operative technique revealed that the nontransannular patch provided a durability advantage when compared with valved conduits, with a trend toward better durability when compared with the transannular patch group. Inability to avoid transannular patch in the newborn period has been cited as a disadvantage of primary repair of TOF/PS in the neonate. ${ }^{10,11}$ The freedom from reoperation in the nontransannular patch group was $88.9 \% \pm 10.5 \%$ at 16 years, and it was $63 \% \pm$ $14.9 \%$ at 14 years in the transannular patch group $(P=$ $.3720)$. The freedom from both reintervention and reoperation was $76.2 \% \pm 14.8 \%$ at 16 years versus $59.5 \% \pm$ $6.8 \%$ at 14 years $(P=.2325)$ in the nontransannular patch group versus the transannular patch group. We failed to appreciate a statistically significant durability advantage of avoiding the transannular patch technique in the neonatal period. The in-hospital survival in our series in the patients with TOF was $93.5 \%$, and it was $90.7 \%$ in the TA group. These results are comparable with those reported in the literature. ${ }^{12-14}$ The use of a transannular patch in the TOF/PS group was $83.1 \%(69 / 83)$, which, once again, is comparable with results in a major series examining neonatal repair of TOF $(81 \%$ [13/16]).

RVOT reconstruction with a monocusp valve construction has been proposed as a potential technique to avoid reoperation for pulmonary insufficiency. Anagnostopoulos and colleagues ${ }^{6}$ have looked at the outcomes of patients with TOF who had RVOT reconstruction with a monocusp valve. They noted that the use of the monocusp valve reduced the incidence of clinically significant postoperative pulmonary insufficiency. Brown and associates ${ }^{5}$ made an observation similar to this: they noted that the use of a monocusp valve during RVOT reconstruction prevented early and midterm pulmonary insufficiency. However, the average ages of the patients in these 2 series were 5.3 months and 3.3 years, respectively, which is significantly higher than in our patient group. The promising result of such a technique in older children has not provided any durability advantage to neonates in our study.

We believe that the type of RVOT reconstruction continues to be lesion specific. Anatomy that is conducive for nontransannular RVOT reconstruction would seem to provide a trend toward a durability advantage. However, we did not appreciate any statistically significant disadvantage of the transannular patch. One of the goals of this study was to identify a type of neonatal RVOT reconstruction that is lasting and durable. However, we have noted that regardless of the type of technique used, there is a certain degree of reoperation or reintervention required. The reoperation rate for the TOF/PS subgroup was $7.2 \%$, which is comparable with that seen in most 1-stage and 2-stage repairs of TOF/PS. ${ }^{11,13}$ The reoperation rates for the TOF/ PA and TOF/APV groups were $47 \%$ and $35.2 \%$, respectively. These results point to the palliative nature of the RVOT reconstruction in these patient subsets. Certain techniques might exhibit durability over the short term, but the RVOT would need to be revised or a competent valve added to the outflow tract at a future date. We perform neonatal correction of TOF, as opposed to palliative procedures, for symptoms such as cyanosis or evidence of hypercyanotic spells. There are several purported advantages of neonatal repair, including the establishment of 2-ventricle circulation early in life, the avoidance of cyanosis, and the establishment of 2-ventricle circulation without the ventricular volume load of the shunt. Additional detriments of not performing a complete neonatal repair include development of right ventricular muscular hypertrophy, which could potentially result in arrhythmogenic focus; distortion of branch pulmonary arteries, requiring additional procedures; and the presence of interstage mortality and morbidity. $3,7,11,14,15$ One study has also shown that the hospital charges for neonatal repair without an intervening shunt were significantly lower. ${ }^{16}$ RVOT reconstruction in neonates with TOF/PS can be accomplished with very little mortality and morbidity. The rates of reintervention and reoperation in our series are comparable with those noted in the literature. The most durable type of RVOT reconstruction that we have noted was the nontransannular patch technique.

The limitations of the study include the fact that it included all different varieties of TOF. However, the main inferences that we can draw from this retrospective review include the fact that the nontransannular patch technique, when possible, provides the most durability advantage. The durability of conduits is limited, and they need to be replaced with some regularity. We have used valve-sparing repair in patients with TOF/PS who had a pulmonary annulus larger than a $z$ score of -2 . Further inspection of specific valve-sparing nontransannular techniques would shed insight into a potentially "curative" technique for the subset of patients with TOF and PS.

\section{References}

1. Castaneda AR, Freed MD, Williams RG, Norwood WI. Repair of tetralogy of Fallot in infancy. Early and late results. J Thorac Cardiovasc Surg. 1977;74:372-81.

2. Barratt-Boyes BG, Neutze JM. Primary repair of tetralogy of Fallot in infancy using profound hypothermia with circulatory arrest and limited cardiopulmonary bypass: a comparison with conventional two-stage management. Ann Surg 1973; 178:406-11.

3. Pigula FA, Khalil PN, Mayer JE, del Nido PJ, Jonas RA. Repair of tetralogy of Fallot in neonates and young infants. Circulation. 1999;100(suppl II):II157-61.

4. Clarke DR, Campbell DN, Pappas G. Pulmonary allograft conduit repair of tetralogy of Fallot. An alternative to transannular patch repair. J Thorac Cardiovasc Surg. 1989;98:730-6.

5. Brown JW, Ruzmetov M, Vijay P, Rodefeld MD, Turrentine MW. Right ventricular outflow tract reconstruction with a polytetrafluoroethylene monocusp valve: a twelve-year experience. J Thorac Cardiovasc Surg. 2007;133: 1336-43. 
6. Anagnostopoulos P, Azakie A, Natarajan S, Alphonso N, Brook MM, Karl TR. Pulmonary valve cusp augmentation with autologous pericardium may improve early outcome for tetralogy of Fallot. J Thorac Cardiovasc Surg. 2007;133:640-7.

7. Duncan BW, Mee RBB, Prieto LR, et al. Staged repair of tetralogy of Fallot with pulmonary atresia and major aortopulmonary collateral arteries. J Thorac Cardiovasc Surg. 2003;126:694-702.

8. Van Praagh R, Van Praagh S. The anatomy of common aorticopulmonary trunk (truncus arteriosus communis) and its embryonic implications. A study of 57 necropsy cases. Am J Cardiol. 1965;16:406-25.

9. Marcelletti C, McGoon DC, Danielson GK, Wallace RB, Mair DD. Early and later results of surgical repair of truncus arteriosus. Circulation. 1977;55: 636-41.

10. Faidutti B, Christenson JT, Beghetti M, Friedli B, Kalangos A. How to diminish reoperation rates after initial repair of tetralogy of Fallot? Ann Thorac Surg. 2002; 73:96-101.
11. Vobecky SJ, Williams WG, Trusler GA, et al. Survival analysis of infants under age 18 months presenting with tetralogy of Fallot. Ann Thorac Surg. 1993;56: 944-50.

12. Hennein HA, Mosca RS, Urcelay G, Crowley DC, Bove EL. Intermediate results after complete repair of tetralogy of Fallot in neonates. J Thorac Cardiovasc Surg. 1995; 109:332-44.

13. Hirsch JC, Mosca RS, Bove EL. Complete repair of tetralogy of Fallot in the neonate. Ann Surg. 2000;232:508-14

14. Van Arsdell GS, Maharaj GS, Tom J, et al. What is the optimal age for repair of tetralogy of Fallot? Circulation. 2000;102(suppl):III123-109.

15. Walsh EP, Rockenmacher S, Keane JF, Hougen TJ, Lock JE, Castaneda AR. Late results in patients with tetralogy of Fallot repaired during infancy. Circulation. 1988;77:1062-7.

16. Ungerleider RM, Kanter RJ, O'Laughlin M, et al. Effect of repair strategy on hospital cost for infants with tetralogy of Fallot. Ann Surg. 1997;225:779-84.

Access to The Journal of Thoracic and Cardiovascular Surgery Online is reserved for print subscribers!

Full-text access to The Journal of Thoracic and Cardiovascular Surgery Online is available for all print subscribers. To activate your individual online subscription, please visit The Journal of Thoracic and Cardiovascular Surgery Online, point your browser to http://www.mosby.com/itcvs, follow the prompts to activate your online access, and follow the instructions. To activate your account, you will need your subscriber account number, which you can find on your mailing label (note: the number of digits in your subscriber account number varies from 6 to 10). See the example below in which the subscriber account number has been circled:

\section{Sample mailing label}

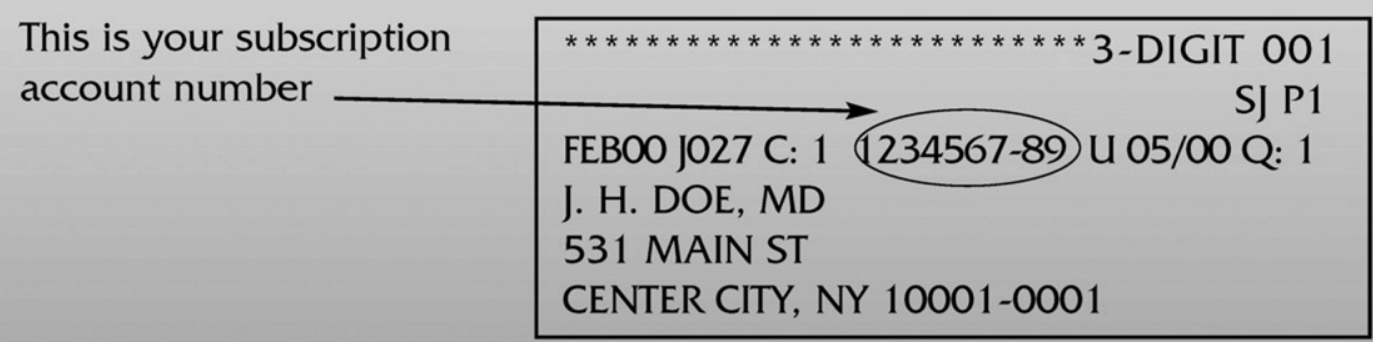

Personal subscriptions to The Journal of Thoracic and Cardiovascular Surgery Online are for individual use only and may not be transferred. Use of The Journal of Thoracic and Cardiovascular Surgery Online is subject to agreement to the terms and conditions as indicated online. 